\title{
LOS PRINCIPIOS DE IGUALDAD Y UNIVERSALIDAD. EXCEPCIONES DE APLICACIÓN A LOS EXTRANJEROS EN SITUACIÓN ADMINISTRATIVA REGULAR EN ESPAÑA: EL CASO DE LA PRESTACIÓN POR HIJO O MENOR A CARGO*
}

\author{
THE EQUALITY AND UNIVERSALITY PRINCIPLES. \\ EXCEPTIONS OF APPLICATION TO FOREIGNERS IN REGULAR \\ ADMINISTRATIVE SITUATION IN SPAIN: THE CASE \\ OF PROVIDING FOR CHILD OR MINOR IN CHARGE
}

\author{
LES PRINCIPES D’ÉGALITÉ ET D’UNIVERSALITÉ. EXCEPTIONS \\ D'APPLICATION AUX ÉTRANGERS EN SITUATION \\ ADMINISTRATIVE ORDINAIRE EN ESPAGNE: CAS \\ DE FOURNITURE D'ENFANT OU DE MINEUR À CHARGE
}

\section{Ana Nieves EsCRIBÁ PÉREZ**}

\begin{abstract}
RESUMEN: Los principios de igualdad y universalidad son básicos en aplicación si lo que se pretende es la consecución de un sistema social sustentado en el Estado social y democrático de derecho. Estos principios básicos son los que deben primar ante todos los individuos que conforman una sociedad, y si bien es cierto que es lo que debemos perseguir y conseguir, existen casos particulares sobre determinadas prestaciones que se convierten en una excepción a la regla, como es el caso de la prestación por hijo o menor a cargo que detalla una serie de connotaciones que, sin pretenderlo en su base, termina siendo no igualitario ni universal para todos los individuos.
\end{abstract}

Palabras clave: principio de igualdad, principio de universalidad, extranjeros, situación administrativa regular, España, prestación por hijo o menor a cargo, seguridad social. 2019.

Recibido el 28 de febrero de 2019 y aceptado para su publicación el 25 de marzo de

** Directora del grado en derecho y profesora de derecho del trabajo y de la seguridad social de la Universidad Internacional de Valencia; doctora en derecho; licenciada en derecho; diplomada en relaciones laborales, y técnica de prevención de riesgos laborales.

\footnotetext{
IS Revista Latinoamericana de Derecho Social Núm. 29, julio-diciembre de 2019, pp. 87-116
} 
ABSTRACT: The principles of Equality and Universality are basic in application if what is intended is the achievement of a social system based on the Social and Democratic State of Law. These basic principles are those that should prevail before all the people that make up a society and, although it is true that it is what we must pursue and achieve, there are particular cases about certain benefits that become an exception to the rule that it is the case of the benefit for a dependent child or minor that details a series of connotations that, without pretending it in its base, end up being not equal or universal for all the people

Keywords: principle of equality, principle of universality, foreigners, regular administrative situation, Spain, provision for dependent child or minor, social security.

RÉSUMÉ: Les principes d'égalité et d'universalité sont d'application fondamentale si l'on veut réaliser un système social fondé sur l'état de droit social et démocratique. Ces principes de base sont ceux qui devraient prévaloir devant tous les individus qui composent une société et, même s'il est vrai que c'est ce que nous devons poursuivre et réaliser, il existe des cas particuliers de certains avantages qui deviennent une exception à la règle comme c'est le cas de la prestation pour enfant à charge ou mineur qui détaille une série de connotations qui, sans le prétendre dans sa base, finissent par ne pas être égales ou universelles pour tous les individus.

Mots-clés: principe d'égalité, principe d'universalité, étrangers, situation administrative normale, Espagne, provision pour enfant à charge ou mineur, sécurité sociale.

SUMARIO: I. Introducción. II. Cuestiones generales. III. Excepciones en la aplicación de los principios de igualdad y universalidad a los extranjeros en España. El caso de la prestación por hijo o menor a cargo. IV. Conclusiones. V. Bibliografía.

\section{INTRODUCCIÓN}

I a Igualdad de trato constituye un derecho imprescriptible de los trabajadores migrantes en tanto hace referencia a un sujeto y un principio fundamental de cualquier coordinación; este principio se ha convertido en la piedra angular de todos los sistemas erigidos en este ámbito con el desarrollo y la complejidad crecientes de los sistemas de seguridad social. 
La igualdad es, sin lugar a dudas, uno de los pilares fundamentales en un Estado social y democrático de derecho como lo es el español; la igualdad debe primar sobre cualquier escenario o interés, ya que es la base fundamental de la universalidad real del sistema.

El principio de universalidad se basa en la consecución de la aplicación del principio de igualdad, teniendo en cuenta que todas las personas son iguales entre ellas, y que, por tanto, tienen los mismos derechos (son iguales ante la ley), y la única manera de llegar a conseguir la aplicación de ambos principios constitucionales es materializarla a través de la igualdad de trato de las personas, independientemente de su situación administrativa, equiparando a los inmigrantes con los nacionales en materia de prestaciones.

Se puede decir que todos los extranjeros (en situación regular y en situación irregular) pueden ser titulares de los derechos naturales, pero que, ciertamente, se hace más complicado que sean acreedores de derechos de distinta naturaleza, ya que se deberá estar a lo dispuesto en el artículo 13.1 de la Constitución española, por lo que dependerán de lo que cada tratado o texto normativo establezca en concreto para el caso en cuestión.

Si se realiza una lectura detallada del artículo 13 de la Constitución española, el lector podrá advertir que el mismo no distingue diferentes estatutos de extranjería, si bien ello no podría justificar un trato desigual entre extranjeros en situación administrativa regular y de los que se encuentran en situación administrativa irregular en España, si bien es cierto que hay que tener en cuenta la realidad socioeconómica del país (y más si cabe la vertiente económica de la misma). El precepto constitucional establece que los extranjeros en España deben disfrutar de todas y cada una de las libertades públicas que garantiza la Constitución española, de acuerdo con lo establecido en los tratados y en la ley, lo que puede justificar un reconocimiento legal limitado de derechos a los extranjeros con relación a los españoles. Obsérvese además, tras dicha lectura detallada del artículo 13, que se evidencia que el legislador constituyente decidió aplicar el principio de igualdad de manera no comparable entre españoles y extranjeros, ya que estableció un principio de equiparación limitada del mismo, consiguiendo la distinción entre ciudadanía extranjera y ciudadanía nacional.

Así, por ejemplo, el Tribunal Constitucional estableció en el fundamento jurídico 4 de su sentencia 107/1984, del 23 de noviembre, y en el fundamento jurídico 5 de su STC 99/1985, del 30 de septiembre, que la Constitución española “...es obra de españoles...”, pero que no queda establecido que sea únicamente “...para españoles...”; es decir, que el artículo 13 de la Cons- 
titución española hace extensible la aplicación de las leyes nacionales a los extranjeros, siempre bajo la interpretación de los tratados y las leyes, pero que, no obstante, existen una serie de derechos que pertenecen a la persona por el mero hecho de serlo, y que, perceptiblemente, serán de aplicación para todos por igual, independientemente de su nacionalidad o situación administrativa. Por otro lado, el alto tribunal remarca que “...el problema de la titularidad y ejercicio de los derechos dependerá...del derecho afectado". Así pues, el Tribunal Constitucional establece que existen una serie de derechos que no pueden ser aplicables a los extranjeros, y son, en concreto, los establecidos en el artículo 23 de la Constitución española; ${ }^{1}$ del mismo modo, existen otro tipo de derechos que serán extensibles a los extranjeros, dependiendo de lo establecido en los tratados y en las leyes, pero asumiendo el trato diferenciado y, por tanto, la falta de adaptación del principio de igualdad, y siendo constitucionalmente admisible la diferencia de trato entre españoles y extranjeros, aunque éstos estén de forma administrativa regular en España. ${ }^{2}$

La seguridad social, en el sistema constitucional español, no está englobada dentro de la categoría de las libertades públicas o de los derechos fundamentales, ni tan siquiera como un derecho constitucional, sino como un principio rector de la política social; partiendo de esa base, en la STC 107/1984 del 23 de noviembre se establecieron los criterios sobre la titularidad de los derechos de los extranjeros en España, y cabe destacar que además de tener derecho al disfrute de los derechos fundamentales, de las libertades públicas y de los derechos constitucionales, se establecía el derecho de los mismos a disfrutar de los principios rectores de la política social y económica (donde se encuentra englobado nuestro sistema de seguridad social).

La Ley Orgánica 4/2000, del 11 de enero, sobre derechos y libertades de los extranjeros en España y su integración social, ${ }^{3}$ regula el derecho a la seguridad social en los artículos 10 y 14, estableciendo que los extranjeros residentes tendrán los mismos derechos que los nacionales en materia de seguridad social; ahora bien, un inciso hace en su artículo 14 sobre los extranjeros en situación administrativa irregular, ya que únicamente les reconoce el acceso a los servicios y a las prestaciones sociales básicas; es cierto que establece la operatividad del principio de igualdad entre extranjeros y españoles para ac-

1 Si bien es cierto que los ciudadanos de la Unión Europea, por ejemplo, sí pueden participar en las elecciones locales.

2 El TC en el fundamento jurídico núm. 5 de su STC 99/1985, del 30 de septiembre y en el fundamento jurídico, núm. 4 de su STC 107/1984, del 23 de noviembre.

3 De ahora en adelante la LO 4/2000. 
ceder a las prestaciones y servicios del sistema de seguridad social, pero hace el inciso de la obligatoriedad, de la residencia legal como requisito indispensable, de modo que el principio de igualdad del artículo 14 de la Constitución española deja de ser efectivo, aunque es cierto que en el artículo 14 de la LO $4 / 2000$ se les reconoce a los extranjeros en situación administrativa irregular las prestaciones básicas.

Cabe recordar que existen ciertos derechos fundamentales que por su naturaleza jurídica, sin lugar a dudas, son derechos de los que debe disfrutar cualquier individuo, independientemente de su nacionalidad; uno de los criterios esgrimidos en la Constitución española para determinar de cuáles se trata es la utilización de los términos "toda persona" o "todos"; ahora bien, del mismo modo, hay que recordar que la LO 4/2000 parte de la aplicación del principio de igualdad entre nacionales y extranjeros en el disfrute de derechos (incluidos los sociales), siendo las únicas diferencias admitidas aquellas establecidas en la propia ley, y que se condiciona a la obtención de la autorización para trabajar o para residir legalmente en España. ${ }^{4}$

Se podría resumir la situación de los extranjeros en España haciendo una lectura simple del artículo 14 de la Ley de Extranjería, que establece que los extranjeros que en situación administrativa regular en España tendrán derecho a acceder a todas y cada una de las prestaciones y servicios de nuestro sistema de seguridad social en las mismas condiciones que un nacional, y hace mención específica tanto a las prestaciones generales y básicas como a las específicas, pero, además, recalca que los extranjeros, independientemente de su situación administrativa en nuestro país (regular o irregular), tendrán derecho a todos y cada uno de los servicios y prestaciones básicos que existen en nuestro sistema de seguridad social. El extracto es sencillo: los extranjeros en situación administrativa regular en España se equiparan a los nacionales, ${ }^{5}$ mientras que los que se encuentran en situación administrativa irregular, únicamente tienen derecho a "los servicios y prestaciones sociales básicos", lo que no hace más que justificar, nuevamente, que no existe un cumplimiento completo del principio de igualdad, y, por tanto, la universalidad del sistema es, claramente, relativa.

4 Según la reforma operada por la Ley Orgánica 8/2000, del 22 de diciembre, de reforma de la LO 4/2000.

5 Moreno Pueyo, M. J., "Extranjeros inmigrantes y seguridad social española", Estudios Financieros. Revista de Trabajo y Seguridad Social: Comentarios, Casos Prácticos: Recursos Humanos, 2004, pp. 123-152. 


\section{CUESTIONES GENERALES}

En lo que a extranjeros se refiere, podemos encontrarnos con diferentes supuestos: extranjeros en situación administrativa regular y extranjeros en situación administrativa irregular en España, lo que supone que el trato que el ordenamiento jurídico español va a conceder a los mismos va a ir en función del estatus del que gocen, es decir, los derechos que les son reconocidos, y el disfrute de los mismos estará unido, directamente, a su situación administrativa.

Con respecto a la titularidad y el ejercicio de los derechos y libertades públicas de los extranjeros, el Tribunal Constitucional ha establecido tres tipos ${ }^{6}$ de situaciones diferenciadas: ${ }^{7}$

- Plenitud de derechos. En esta primera situación se encontrarían los derechos que corresponden de igual modo a extranjeros y nacionales, cuyo ejemplo más importante sería el derecho a la vida y a la integridad física y moral; si hablamos del caso que me ocupa, la asistencia sanitaria estaría englobada dentro de esta categoría de derechos. ${ }^{8}$

- Carencia de derechos. Se referiría a los derechos que no pertenecen en modo alguno a los extranjeros; por ejemplo, el derecho a participar en los asuntos públicos, directamente o por medio de representantes, libremente elegidos en elecciones periódicas por sufragio universal. ${ }^{9}$

- Potencial titularidad de derechos. Los derechos cuya titularidad comparten nacionales y extranjeros, si bien el ejercicio por estos últimos se condiciona a lo establecido por los tratados y las leyes.

\section{Los extranjeros y las autorizaciones administrativas para residir y trabajar legalmente en España}

La diferencia entre inmigrantes en situación regular e inmigrantes en situación irregular en España ya se establecía en la exposición de motivos de la

6 En este sentido SSTC 17/2013, del 31 de enero; 236/2007, del 7 de noviembre; 4/1985, de 18 de enero y 107/1984, del 23 de noviembre.

7 Triguero Martínez, L. A., El estatuto jurídico laboral del trabajador extranjero inmigrante, Albacete, Bomarzo, 2008, pp. 55-60.

8 Fernández Bernat, J. A., "Asistencia sanitaria e inmigración irregular", Revista de treball, economia i societat, núm. 67, 2013, pp. 1-16.

9 Si bien la Ley de Bases reguladora del Régimen Local sí reconoce este derecho a ciudadanos de la UE y a los extranjeros en situación regular, si se dan condiciones de reciprocidad con su país de origen. 
Ley Orgánica $7 / 1985,{ }^{10}$ donde se reconocía el ejercicio efectivo de derechos y la aplicación de garantías frente a éstos, a todos y cada uno de los extranjeros que se encontraran en España de forma regular, pero a su vez establecía una serie de medidas de aplicación que impedían la presencia de extranjeros en situación administrativa irregular. ${ }^{11}$

El artículo 1o. del TRLGSS es el que establece el derecho de los españoles a disfrutar de nuestro sistema de seguridad social siguiendo el mandato establecido en el artículo 41 de nuestra Constitución, y, de tal modo, queda claro que todos los españoles tienen derecho a la seguridad social, pero nada dice de los trabajadores extranjeros, aunque si atendemos a lo que se establece en el artículo 7.1 de la misma norma que prevé que quedan comprendidos en el ámbito de aplicación del TRLGSS todos los españoles y los extranjeros en situación administrativa regular en el país siempre y cuando lleven a cabo su actividad laboral dentro del territorio nacional, se hace extensible el ámbito subjetivo de aplicación del sistema ya no sólo a todos los españoles, sino a los extranjeros "que residan o se encuentren legalmente en España", de modo que el propio texto legal nos adelanta cuál va a ser la situación de los extranjeros en situación administrativa regular en España equiparándolos a los nacionales y realizando una interpretación restrictiva del principio de igualdad y del principio de universalidad, para declarar, una vez más, que ambos son principios relativos en nuestro sistema de seguridad social. Nos adelantan ambos preceptos legales que la capacidad para trabajar del extranjero, y, por tanto, la posibilidad de quedar incluido dentro del sistema de seguridad social, va a depender en mayor medida de las autorizaciones administrativas, que de criterios de carácter social o laboral. ${ }^{12}$

Hay que aclarar que, conforme a la legislación actual en la materia y su relación con la Constitución española y los mandatos internacionales y europeos, no existe vulneración del principio de igualdad de trato entre españoles y extranjeros en situación administrativa regular o irregular en nuestro país, ya que, claramente, los extranjeros en situación administrativa regular gozan de los mismos derechos que los nacionales, y a los que están en situación ad-

10 Ley Orgánica 7/1985, del 1o. de julio, sobre derechos y libertades de los extranjeros en España. (Vigente hasta el 1o. de febrero de 2000).

11 Montoya Melgar, A., El empleo ilegal de inmigrantes, Cizur Menor, Navarra, ThomsonCivitas, 2007, p. 37.

12 Sirvent Hernández, N., "La residencia legal como requisito de acceso a la protección de seguridad social de los extranjeros extracomunitarios", Revista General de Derecho del Trabajo y de la Seguridad Social, 2009, p. 20. 
ministrativa irregular se les dota de las protecciones sociales básicas, es decir, aquellos que van unidos a su condición de personas, a los derechos humanos consagrados a lo largo de la historia y, sobre todo, los que van encaminados a la protección de la vida o de la integridad física (porque sí se les reconoce la asistencia sanitaria de urgencia), si bien es cierto que en el ámbito del derecho del trabajo y del derecho a la seguridad social se les otorga un trato preferente a aquellos extranjeros que se encuentran en situación administrativa regular en España; no obstante, en lo que a las prestaciones se refiere, el caso de los extranjeros en situación administrativa irregular ha llevado a la doctrina y a la jurisprudencia a defender los derechos de estos trabajadores que por su situación administrativa quedaban fuera del campo de aplicación del sistema en prestaciones tales como el desempleo, el accidente de trabajo o la enfermedad profesional (prestaciones, todas ellas, típicas del trabajador encuadrado dentro del sistema de seguridad social); en su fundamento jurídico núm. 7 de la STC 259/2007, del 19 de diciembre, el Tribunal Constitucional estableció que la legalidad o ilegalidad de la situación de un extranjero en España no influye para entender que ha desarrollado o desarrolla un trabajo por cuenta ajena para un empleador, reconociendo al extranjero en situación administrativa irregular, el derecho a la huelga.

El artículo 7o. del TRLGSS establece las barreras existentes entre el acceso a las prestaciones de carácter contributivo y las de carácter no contributivo, y es de resaltar que la nacionalidad y la residencia se convierten en requisitos indispensables para poder acceder al sistema de seguridad social).

Se podría afirmar que nuestro sistema de seguridad social limita el acceso a la misma, más que a través del criterio de la nacionalidad, basándose en el criterio de la residencia (legal) del sujeto; así, la nacionalidad, la residencia o la situación legal del extranjero en España son factores indispensables.

El artículo 36.5 de la LO 4/2000 establece, en cuanto a los trabajadores extranjeros en situación administrativa irregular en España, que "para la obtención de las prestaciones derivadas de supuestos contemplados por los convenios internacionales de protección a los trabajadores u otras que pudieran corresponderle, siempre que sean compatibles con su situación”, que, interpretado, conjuntamente con el Convenio núm. 97 de la OIT, que regula la protección de los trabajadores migrantes y que se encuentren en situación administrativa regular, para los que el artículo 36.5 de la LO 4/2000 in fine, establece, por ejemplo, que aquel trabajador que no esté en situación administrativa regular en España no podrá acceder a la prestación por desempleo, introduciendo así, ya una clara diferenciación entre unos y otros. Asimismo, 
el artículo 14.3 de la LO 4/2000 instituye que los extranjeros en situación administrativa irregular en España y que, por tanto, no realicen una actividad laboral (por la imposibilidad de hacerlo por motivos obvios), solamente podrán ser beneficiarios de las prestaciones y servicios básicos de nuestro sistema de seguridad social.

Uno de los ítems diferenciadores a la hora del reconocimiento de ciertos derechos a los extranjeros en España viene establecido por los criterios de ciudadanía y residencia legal de los mismos; por ejemplo, en la STC 236/2007, del 7 de noviembre, y en la STC 259/2007 del 19 de noviembre se declaró inconstitucional la exigencia de residencia legal en lo que se refería, por ejemplo, al derecho de asociación, la libertad sindical o el derecho a la huelga, que, por tanto, quedan ahora abiertos a la participación y disfrute de los extranjeros en situación administrativa irregular en España (cosa que no ha ocurrido en el acceso al sistema de seguridad social en todas sus áreas). Hay que recordar también que la regulación de la situación de los trabajadores extranjeros, en lo que al sistema de seguridad social se refiere, es potestad del legislador ordinario, que lo podrá regular, tanto por ley orgánica, cuando afecte a alguna de las materias previstas en el artículo 81 de la Constitución española, como por ley ordinaria, en los demás casos; de este modo, y en palabras del Tribunal Constitucional en el fundamento jurídico 4o. de su STC 107/1984, del 23 de noviembre: "El legislador goza, en cambio, de mayor libertad al regular los derechos de los que serán titulares los extranjeros en la medida y condiciones que se establezcan en los Tratados y las Leyes"; es decir, puede decidir si aplicar las leyes o no en los mismos términos que lo hace con los españoles, y, por tanto, introducir tratamientos desiguales para extranjeros y nacionales; en la misma sentencia establece, asimismo, el máximo intérprete de la carta magna, que el legislador, en cualquier caso, puede tener en cuenta la situación administrativa del extranjero en España y exigirla para ejercer algunos de los derechos que la Constitución española reconoce, teniendo en cuenta que para el disfrute de ellos es necesario entrar y permanecer en territorio español en situación administrativa regular, eso sí, siempre limitado por las exigencias del artículo 10.2 de la Constitución española .

La Tesorería General de la Seguridad Social, en su circular del 5 de abril de 2001, establecía que para entender que exista obligación de cotizar era necesario que el trabajador extranjero contara obligatoriamente con el permiso de trabajo, lo que derivó en la Ley 62/2003, del 30 de diciembre, de medidas fiscales, administrativas y del orden social, que en su artículo 48 establecía sanción al empresario que empleara a extranjeros en situación 
administrativa irregular, que equivaldría a la cantidad de las cotizaciones que hubiera debido ingresar, de haber contado el extranjero con todos los permisos pertinentes.

Así, la realidad jurídica del extranjero en situación administrativa irregular en España podría entenderse como una falta de "legitimación para trabajar y residir en España", que es lo que realmente le concede la autorización administrativa pertinente. Esta falta de legitimación puede razonarse como una prohibición legal expresa para realizar cualquier tipo de trabajo en territorio español; también nos podemos apoyar en la idea de que dicho contrato está viciado en cuanto a su objeto y su causa se refiere, y, por tanto, estaríamos ante "un objeto negocial ilícito", que, obviamente, nos conduciría a la invalidación del contrato. Parte de la jurisprudencia y en aplicación de la primera Ley de Extranjería, la Ley Orgánica 7/1985 13 calificaba como nulo dicho contrato de trabajo según lo establecido en los artículos 6.3 y 1.275 del Código Civil, y en los artículos 7.c) y 9.3 del anterior estatuto de los trabajadores hasta la aparición de la nueva redacción del artículo 36.5 de la LO 4/2000, donde se establecía que la carencia de la pertinente autorización administrativa no era causa de invalidación del contrato de trabajo del extranjero en situación administrativa irregular en España, por lo que parte de la jurisprudencia y de la doctrina declaraban que el contrato de trabajo suscrito con un extranjero en situación administrativa irregular en España surtía efectos para el empleador y el trabajador con todo lo que ello conlleva. ${ }^{14}$

La STS del 18 de marzo de $2008^{15}$ diferencia dos situaciones; la primera, la de los contratos de trabajo celebrados con extranjeros en situación administrativa regular en España, pero que carecen de permiso de trabajo, y la segunda, de los extranjeros en situación administrativa irregular en España que carecen tanto de permiso de trabajo como de residencia; ${ }^{16}$ la citada sentencia reconoce que para el primer supuesto, el contrato de trabajo celebrado con el extranjero en situación administrativa regular en España supone el acceso a las prestaciones tanto contributivas como no contributivas del sistema de se-

13 Ley Orgánica 7/1985, del 1o. de julio, sobre derechos y libertades de los extranjeros en España (vigente hasta el 1 de febrero de 2000).

14 Montoya Melgar, A., "El empleo ilegal de inmigrantes", Revista de Derecho de la Unión Europea, 2009, pp. 17-32.

15 Número de recurso 800/2007.

16 Ortega Giménez, A., "El derecho a la prestación por desempleo de los extranjeros irregulares, tras la sentencia del tribunal supremo de 18 de marzo de 2008", Actualidad Jurídica Aranzadi, 2008, pp. 1-6. 
guridad social, mientras que en el segundo caso, solamente reconoce el acceso a las prestaciones y servicios sociales básicos, contingencias profesionales y asistencia sanitaria. ${ }^{17}$

El Convenio $19^{18}$ de la OIT también reconoce igualdad de trato, independientemente de la situación administrativa del extranjero, con relación a los accidentes de trabajo y enfermedades profesionales, ahora bien, con ciertos requisitos; por otro lado, el artículo 14 de la LO 4/2000 establece la igualdad de trato en materia de seguridad social, pero lo hace en referencia a los extranjeros residentes, lo que conlleva a que serían de aplicación y podrían disfrutar tanto de las pensiones contributivas como de las no contributivas; pero no hay que olvidar que el artículo 7o. del TRLGSS instaura que tendrán derecho a incluirse en el sistema de seguridad social aquellos extranjeros que gocen de la condición de regular en nuestro país, en lo que a permiso de residencia y de trabajo se refiere. ${ }^{19}$

Lo primero que se debe determinar es cómo afecta la situación administrativa irregular de un extranjero a la hora de recibir protección por parte del sistema de seguridad social español en su modalidad contributiva, ya que la situación administrativa irregular puede deberse tanto a la permanencia en nuestro país como a la autorización para trabajar, ${ }^{20}$ que además es posible que se produzcan a la vez.

Los artículos 14.1 y 14.2 de la LO 4/2000 dejan en claro que los extranjeros residentes tendrán derecho a las prestaciones y servicios de la seguridad social (cosa obvia, si desarrollan su vida en idénticas condiciones a los nacionales), de lo que se desprende que quedan fuera los extranjeros en situación irregular en España; además, debemos hacer una lectura completa del artículo

17 Sánchez Rodas-Navarro, C., Derechos sociales, garantias y restricciones de los inmigrantes en situación irregular en la unión europea, Murcia, Laborum, 2008.

18 C019 - Convenio sobre la igualdad de trato (accidentes del trabajo), 1925 (núm. 19). Convenio relativo a la igualdad de trato entre los trabajadores extranjeros y nacionales en materia de indemnización por accidentes del trabajo (entrada en vigor: 8 septiembre 1926). Adopción: Ginebra, 7a. reunión CIT (5 de junio de 1925) - Estatus: Instrumento en situación provisoria (convenios técnicos).

19 Álvarez Cortés, J. C. y Plaza Angulo, J. J., "Prestaciones de seguridad social. Sobre la imposibilidad de acceder a la protección por desempleo por los trabajadores inmigrantes en situación irregular", Temas Laborales: Revista Andaluza de Trabajo y Bienestar Social, 2008, pp. 223-238.

20 Sánchez-Urán Azaña, Y., "Derecho a la protección social como factor de integración del inmigrante. La dialéctica universalidad/ciudadanía", Revista del Ministerio de Trabajo e Inmigración (63), 2006, pp. 249-296. 
14, y en concreto, de su apartado 3 , que establece que los extranjeros, cualquiera que sea su situación administrativa, tienen derecho a los servicios y a las prestaciones sociales básicas, que no tienen por qué entenderse que son las comprendidas en el sistema de seguridad social, ya que, como se ha visto antes, debe interpretarse a tenor de los artículo 7,15 y ss. del Real Decreto Legislativo 8/2015, del 30 de octubre, por el que se aprueba el texto refundido de la Ley General de la Seguridad Social.

\section{Los extranjeros en situación administrativa regular en España} y el derecho a la seguridad social

En este punto voy a centrar mi interés en el caso de los extranjeros en situación administrativa regular en España y en el otorgamiento y disfrute de los derechos sociales de los mismos; así, se reconocen para ellos derechos tales como la educación, la asistencia sanitaria, las prestaciones y los servicios del sistema de seguridad social tal y como establece el artículo 13 de la LO 4/2000, tras la reforma operada por la Ley Orgánica 2/2009, del 11 de diciembre. $^{21}$

El más sencillo de todos los casos es, evidentemente, el caso de los inmigrantes en situación regular en España; con el paso de los años y gracias al trabajo de los tratados internaciones, nuestro ordenamiento jurídico y, por supuesto, el compromiso de los órganos judiciales españoles, han propiciado un gran avance en cuanto a la equiparación de derechos entre extranjeros en situación regular y españoles en nuestro sistema legislativo en general y en el sistema de seguridad social en concreto.

Si nos remontamos a la Ley $7 / 1985,{ }^{22}$ del 1o. de julio, hay que destacar que ésta regulaba la situación de los extranjeros como una mera cuestión de orden público, ${ }^{23}$ pero en la LO 4/2000 se estableció un sistema que ya se desarrollaba con base en lo establecido en la STC 107/1984, del 23 de noviembre, y que después reafirmaba la STC 95/2000, del 10 de abril, y, por tanto, en la

21 Ley Orgánica 2/2009, del 11 de diciembre, de reforma de la LO 4/2000.

22 Ley Orgánica 7/1985, del 1o. de julio, sobre derechos y libertades de los extranjeros en España (vigente hasta el 1o. de febrero de 2000).

23 Pumar Beltrán, N., "Protección social y familiares de las personas trabajadoras extranjeras en España”, El futuro europeo de la protección social, Murcia, Laborum, 2010, pp. 251 261. 
doctrina elaborada por el Tribunal Constitucional, ${ }^{24}$ en la que se reconocían los derechos "imprescindibles para garantizar la dignidad humana". 25

Como antecedente lógico de todo ello, comenzaré señalando que el aumento migratorio inició en España a partir de la década de los ochenta, por lo que el legislador tuvo que tomar medidas para controlar los flujos de personas y la lucha contra la inmigración irregular, aunque si bien es cierto, España, a partir de su adhesión al Tratado de Ámsterdam, en virtud de instrumento aprobado mediante la LO 9/1998, ${ }^{26}$ ha intentado adaptar los objetivos en él establecidos a su legislación interna. Tras la aprobación del Tratado de Ámsterdam, la Unión Europea asumió las competencias relativas a las políticas de asilo e inmigración, y, así, fue el Pacto Europeo sobre Inmigración y Asilo, del 24 de septiembre de 2008, el que se ocupó de esta materia y estableció las pautas a seguir en la lucha contra la inmigración ilegal y la inserción social de los inmigrantes; pero hay que destacar que la necesidad de mano de obra en décadas anteriores en nuestro país propició la migración desde ciertos países, y que, por tanto, las políticas migratorias iban directamente relacionadas con las demandas de nuestro mercado de trabajo. ${ }^{27}$ Será la situación económica del país de destino, entre otros factores, lo que determinará el modo de desarrollo y aplicación de la legislación en la materia, ya que las políticas migratorias se ponen al servicio del mercado de trabajo. ${ }^{28}$

Fue más tarde, con la aprobación en España de la LO 4/2000, cuando se reforzó definitivamente el principio de igualdad, ya que prevé en su artículo 14.1, que los extranjeros en situación regular deberían gozar de los mismos

24 Rivera Sánchez, J. R., "La acción protectora derivada de contingencias profesionales a los trabajadores extranjeros en situación irregular. Comunicación a la ponencia temática III", Derechos y libertades de los extranjeros en España: XII Congreso Nacional de Derecho del Trabajo $y$ de la Seguridad Social, Santander, Gobierno de Cantabria, Consejería de Industria, Trabajo y Desarrollo Tecnológico, 2003, pp. 1345-1364.

25 Pumar Beltrán, N., "Protección social y familiares de las personas trabajadoras extranjeras en España”, El futuro europeo de la protección social, cit., pp. 251-261.

26 Ley Orgánica 9/1998, del 16 de diciembre, por la que se autoriza la ratificación por España del Tratado de Ámsterdam, por el que se modifican el Tratado de la Unión Europea, los tratados constitutivos de las comunidades europeas y determinados actos conexos, firmado en Ámsterdam el 2 de octubre de 1997.

27 López López, J., "Una mirada a los derechos sociales de los inmigrantes desde su dignidad”, Estudios de Derecho Judicial, 2005, pp. 23-52.

28 Ramos Quintana, M. I., "Inmigración y globalización económica: ¿un lugar para el derecho del trabajo?", Revista del Ministerio de Trabajo e Inmigración, 2006, pp. 13-32. 
beneficios en lo que a materia de seguridad social se refiere; esto supuso un gran avance en el camino de la consecución y adaptación del principio de igualdad y, por ende, de la universalización del sistema (eso sí, una vez más hablamos de universalidad relativa, ya que únicamente tratamos el tema de los extranjeros regulares y sus derechos dejando de lado, de nuevo, el problema de los extranjeros en situación administrativa irregular). En este sentido, es cierto que en la LO 4/2000 se establece que los extranjeros en situación administrativa irregular tienen derecho a la asistencia sanitaria básica de urgencia.

En materia de seguridad social se debe enfatizar la reforma del artículo 7o. del TRLGSS con su nueva redacción, y que sirvió para adaptar nuestro ordenamiento jurídico a lo establecido en el artículo 6o. del Convenio 9729 de la OIT sobre trabajadores migrantes, en el que se nos obligaba a equiparar a los extranjeros residentes con los españoles, en lo que a prestaciones contributivas $^{30}$ se refería, si bien es cierto que este tipo de equiparación no se producía en las pensiones no contributivas, y así se reflejaba en el artículo 7.5 del TRLGSS. No obstante, tal diferenciación desaparece con la redacción del artículo 14.1 de la LO 4/2000, mediante el cual se hace extensiva dicha igualdad de trato a las prestaciones no contributivas, consiguiendo así, la equiparación total al nacional. ${ }^{31}$

Se puede afirmar, en lo relativo a extranjeros en situación administrativa regular, que tras las diversas modificaciones establecidas en las leyes para su adaptación a los mandatos establecidos por convenios ratificados por España, éstos gozan de los mismos derechos que los nacionales, y en lo que se refiere al derecho a la seguridad social disfrutan de los mismos derechos que los nacionales, siempre que estén incluidos en el sistema por realizar o haber realizado trabajo remunerado en nuestro país.

29 C097 - Convenio sobre los trabajadores migrantes (revisado), 1949 (núm. 97). Convenio relativo a los trabajadores migrantes (revisado en 1949) (entrada en vigor: 22 de enero de 1952). Adopción: Ginebra, $32^{\text {a }}$ reunión CIT (1o. de julio de 1949), estatus: Instrumento actualizado (convenios técnicos).

30 Incluso, la reforma de la ley 13/1996, al mencionar a todos los extranjeros extiende la equiparación a colectivos que tradicionalmente habían sido excluidos en los convenios bilaterales, como los trabajadores autónomos. Gonzalo Gonzáles, B., "Apunte sobre los derechos de seguridad social de los extranjeros en España tras la Ley 13/1996, del 30 de diciembre", Revista del Ministerio de Trabajo e Inmigración, núm. 2, 1997, pp. 98 y ss.

31 Sánchez-Urán Azaña, Y., "Derecho a la protección social como factor de integración del inmigrante. La dialéctica universalidad/ciudadanía", cit., pp. 249-296. 
Con relación a este colectivo, el ordenamiento jurídico español, en materia de seguridad social, se ajusta en su totalidad al cumplimiento del principio de igualdad, y, por lo tanto, supone una equiparación en lo que al principio de universalidad se refiere en relación con los nacionales; esto quiere decir que se ha conseguido extender el campo de aplicación del sistema de seguridad social haciéndolo más igualitario para los sujetos incluidos en este colectivo, y por tanto, acercándolo más a la consecución de la universalidad del sistema; eso sí, sin dejar de ser universalidad relativa.

En el tema que me ocupa, es decir, en materia de derechos sociales, hay que resaltar que con la vigencia de las actuales leyes de extranjería ${ }^{32}$ y las leyes que regulan los derechos sociales, aquellos extranjeros que se encuentren en situación regular en España tienen los mismos derechos que los españoles en materias tales como educación, asistencia sanitaria, prestaciones y servicios de la seguridad social..., todos ellos, derechos básicos.

A través de la legislación, los tratados internacionales y la interpretación del Tribunal Constitucional y del Tribunal Supremo se ha llevado a cabo un gran trabajo de consecución de un mayor reconocimiento de los derechos laborales y de seguridad social establecidos en nuestro ordenamiento jurídico; así pues, la aprobación de la LO 4/2000 instituyó un estatuto jurídico para los extranjeros teniendo en cuenta los derechos imprescindibles para garantizar la dignidad humana y el resto de derechos que se veían condicionados a la situación regular o irregular del extranjero ${ }^{33}$ en España. ${ }^{34}$

Si bien es cierto que la equiparación entre nacionales y extranjeros en situación administrativa regular en España tiene un grado de adaptación importante, siguen apareciendo problemas de aplicación de dicho principio, que limitan el acceso a determinadas prestaciones, y, que a su vez, plantean cuestiones tales como la igualdad real del sistema de seguridad social, y que se puede apreciar en el caso de la prestación por hijo o menor a cargo que está legislada, de tal modo que establece una serie de diferencias que en su gran mayoría afectan a los extranjeros más que a los nacionales.

32 Ley Orgánica 2/2009, del 11 de diciembre, de reforma de la LO 4/2000.

33 SSTC 263/2007, del 20 de diciembre, 264/2007, del 20 de diciembre, 236/2007, del 7 de noviembre.

34 Rodríguez-Piñero Royo, M., "Principio de igualdad y estatuto del trabajador inmigrante", Relaciones Laborales. Revista Crítica de Teoría y Práctica, 2001, pp. 91-106. 


\section{Evolución normativa en materia de contratos celebrados con extranjeros} y su consideración legal en España

La evolución de la normativa en materia de extranjería se podría resumir en cinco etapas diferenciadas, coincidiendo con los cinco cambios legislativos más importantes en la materia, así pues: ${ }^{35}$

- Tras la aprobación de la Ley Orgánica 7/1985, del 1o. de julio, sobre derechos y libertades de los extranjeros en España (vigente hasta el 10. de febrero de 2000). En esta primera etapa, tanto la jurisprudencia como la doctrina entendían que si no existía la preceptiva autorización administrativa para trabajar en España, el contrato de trabajo celebrado con el extranjero en situación administrativa irregular en España se consideraba nulo, y el extranjero en situación administrativa irregular, únicamente generaba derecho a la percepción de los salarios correspondientes al tiempo trabajado, ${ }^{36}$ si bien es cierto que se solía permitir la percepción de la prestación por desempleo en caso de que no contara con permiso de trabajo, pero sí con el de residencia. La Ley Orgánica 7/1985 establecía en su artículo 15 que todos los extranjeros que decidan establecer en España su residencia habitual y, además, llevar a cabo cualquier actividad lucrativa (laboral o profesional), han de obtener, por un lado, el permiso de residencia otorgado por el Ministerio del Interior, y, por otro, el permiso de trabajo otorgado por el Ministerio de Trabajo y Seguridad Social, ${ }^{37}$ de modo que la falta del pertinente permiso suponía la expulsión del extranjero en situación administrativa irregular, a tenor del artículo 26.1.b) de la misma, y la sanción correspondiente al empresario, a tenor del artículo 28; el extranjero dependía de lo establecido en el artículo 7o. del Estatuto de los Trabajadores en lo referente a la capacidad para contratar, y al no cumplir los requisitos establecidos se reconocía la nulidad del contrato, y, por tanto, no era posible entender que el mismo generara ningún derecho; no obstante lo anterior, la STS del 21 de diciembre de $1994^{38}$ estableció, en este sentido, que si expiraba

35 Martínez Fons, D., "Los efectos del despido de los trabajadores extranjeros que carecen de autorización administrativa para trabajar en España”, sentencia del Tribunal Superior de Justicia de Castilla y León del 17 de noviembre de 2005 (AS 3384), Iuslabor, 2006.

36 A tenor del artículo 9.2 del Estatuto de los Trabajadores.

37 Ambos tendrán una validez de cinco años.

38 Número de recurso 785/1994. 
la autorización administrativa para trabajar pero continuaba vigente la autorización para residir el extranjero podía buscar empleo y generar un nuevo derecho a obtener la autorización administrativa para trabajar y, como conclusión, mientras el extranjero mantuviera autorización para residir legalmente en España, tenía derecho a percibir la prestación por desempleo, siempre y cuando hubiera cumplido con los requisitos de afiliación, alta y cotización. En 1997, el tribunal supremo, en su sentencia del 21 de marzo, ${ }^{39}$ estableció, con base en los artículo 6.3 y 1275 del Código Civil y el artículo 7o. del Estatuto de los Trabajadores, que los contratos de trabajo celebrados con extranjeros en situación administrativa irregular en España debían considerarse ilícitos, y, por tanto, no producían efecto alguno, por lo que los trabajadores extranjeros en situación administrativa irregular que celebraban este tipo de contratos no tenían derecho de acceso a la prestación por desempleo ${ }^{40} \mathrm{o}$ accidente de trabajo, y así lo establecía la jurisprudencia, ya que entendía que una de las partes carecía de capacidad para contratar. ${ }^{41}$ De tal modo, se declaraba el contrato de trabajo nulo de pleno derecho. ${ }^{42}$

- Tras la aprobación de la Ley Orgánica 4/2000, del 11 de enero, sobre derechos y libertades de los extranjeros en España y su integración social. En esta segunda etapa se produce un giro absoluto en cuanto a la validez de los contratos de trabajo celebrados con los extranjeros en situación administrativa irregular en España, motivado, en gran parte, por la utilización de los empresarios de mano de obra de extranjeros en situación administrativa irregular originada por la llegada masiva de inmigrantes a España durante la década de los noventa, provocando que los empresarios se beneficiaran de dicha cuestión legal para emplear mano de obra ilegal y barata, ${ }^{43}$ cosa que ocurrió hasta la reforma de $2003 ; 44$ así pues, se

39 Idem.

40 Charro Baena, P., "Trabajadores extranjeros «ilegales» y accidente de trabajo y enfermedad profesional. Cobertura en el sistema de seguridad social", Accidentes de trabajo y enfermedades profesionales, Cizur Menor (Navarra), Aranzadi, 2007, pp. 371-377.

41 Por ejemplo, en ATS del 1o. de julio de 1987 (Roj 561/1987).

42 En este sentido, STS del 21 de marzo de 1997, número de recurso 2068/1996.

43 Sánchez Pérez, J., "El accidente de trabajo del inmigrante «sin papeles»", Actas del I Congreso Internacional sobre Migraciones en Andalucía, Universidad de Granada, Instituto de Migraciones, 2011, pp.793-803.

44 En este sentido se pronunciaba la STC 107/84, del 23 de noviembre, donde el Tribunal Constitucional no consideraba vulnerado el principio de igualdad de los extranjeros justificando su decisión en que en materia de acceso al trabajo no resulta exigible desde una 
convierte en una norma que introduce (ya en su título) la integración social de los extranjeros en España. El carácter de dicha norma es mucho más laxo que el de la anterior (la Ley Orgánica 7/1985, del 1o. de julio), que a su vez pretende garantizar la aplicación del principio de igualdad. ${ }^{45}$ De este modo, se entendía que la falta de la preceptiva autorización administrativa no suponía la invalidez del contrato de trabajo; ${ }^{46}$ en el artículo 57 de la LO 4/2000 se establecía que no procedía la expulsión de los trabajadores extranjeros en situación administrativa irregular en España si eran beneficiarios de una prestación por incapacidad permanente a causa de un accidente de trabajo o una enfermedad profesional surgidas como consecuencia de un trabajo en España.

- Tras la aprobación de la Ley Orgánica 8/2000, del 22 de diciembre, de reforma de la Ley Orgánica 4/2000, del 11 de enero, sobre derechos y libertades de los extranjeros en España y su integración social. En esta tercera etapa, muy solapada a la segunda, por la fecha de la reforma de la anterior ley, se da un nuevo giro en el tratamiento de los extranjeros en situación administrativa irregular en España. Se producen recortes en lo que a los derechos de los extranjeros en nuestro país con respecto a la norma anterior, volviendo a exigir las preceptivas autorizaciones de residencia y trabajo, tal y como establece en su artículo 36, pudiéndose desprender del citado artículo que el contrato de trabajo suscrito con un extranjero en situación administrativa irregular no es considerado nulo, por lo que tendrá derecho a las prestaciones derivadas de la seguridad social. En las SSTS del 7 de junio ${ }^{47}$ y del 9 de octubre de $2003,{ }^{48}$ la Sala $4 a$. del Tribunal Supremo estableció que los contratos de trabajo, a tenor de la nueva legislación, no eran nulos, y que, por tanto, el trabajador extranjero en situación administrativa irregular tenía derecho a la misma protección que cualquier otro trabajador, entendiendo, por ejemplo, que los acci-

óptica constitucional la igualdad de trato entre extranjeros y españoles cuando no existe tratado que así lo imponga.

45 Ramos Quintana, M. I., "El trabajo de los inmigrantes extracomunitarios. Situaciones administrativas y posición jurídica", ponencia temática II. Derechos y libertades de los extranjeros en España: XII Congreso Nacional de Derecho del Trabajo y de la Seguridad Social, Santander, Gobierno de Cantabria, Consejería de Industria, Trabajo y Desarrollo Tecnológico, 2003, pp. 489-571.

46 Sánchez Pérez, J., "El accidente de trabajo del inmigrante "sin papeles»", Actas del I Congreso Internacional sobre Migraciones en Andalucia, cit., pp. 793-803.

47 Número de recurso 4217/2002.

48 Número de recurso 2153/2002. 
dentes de trabajo sufridos por los trabajadores extranjeros en situación administrativa irregular en España eran responsabilidad del empresario.

- Tras la reforma de la Ley Orgánica 14/2003, del 20 de noviembre, de Reforma de la Ley Orgánica 4/2000, del 11 de enero, sobre derechos y libertades de los extranjeros en España y su integración social, modificada por la Ley Orgánica 8/2000, del 22 de diciembre; de la Ley 7/1985, del 2 de abril, Reguladora de las Bases del Régimen Local; de la Ley 30/1992, del 26 de noviembre, de Régimen Jurídico de las Administraciones Públicas y del Procedimiento Administrativo Común, y de la Ley 3/1991, del 10 de enero, de Competencia Desleal. En esta cuarta etapa se le otorga una nueva redacción al artículo 36, y pasa a establecerse que la carencia de la pertinente autorización no invalidará el contrato de trabajo en lo que a derechos del trabajador se refiere, incluido el derecho a la percepción de las prestaciones que pudieran corresponderle en materia de seguridad social, incluidas tanto las derivadas de contingencias profesionales como de contingencias comunes (comprendido el desempleo). En este sentido, si un empresario no solicita la autorización administrativa para trabajar del extranjero en situación irregular en España, de conformidad con lo previsto en el artículo 36 de la Ley Orgánica 14/2003, las consecuencias derivadas de la falta de autorización no deben recaer sobre el trabajador. ${ }^{49}$

- Tras la Ley Orgánica 2/2009, del 11 de diciembre, de reforma de la Ley Orgánica 4/2000, del 11 de enero, sobre derechos y libertades de los extranjeros en España y su integración social. En esta última etapa vuelve a producirse un cambio importante en cuanto a los extranjeros en situación administrativa irregular en España. El artículo 10.1 establece que todos los extranjeros residentes en España que reúnan los requisitos establecidos en la propia LO 4/2000 podrán ejercer actividades remuneradas, tanto por cuenta propia como cuenta ajena y, por supuesto, acceder al sistema de seguridad social; así, el artículo 10.1 de la presente Ley incluye el término "residentes" en su redacción, de modo que aquellos que no cuenten con la preceptiva autorización administrativa para trabajar no podrán hacerlo. Se establece, taxativamente, el trato igualitario entre nacionales y extranjeros en situación administrativa regular en España, en lo que se refiere a las condiciones laborales y de acceso al sistema de seguridad social.

49 Sentencia TSJ Castilla y León, con sede en Valladolid, del 17 de noviembre de 2005. 


\section{EXCEPCIONES EN LA APLICACIÓN DE LOS PRINCIPIOS \\ DE IGUALDAD Y UNIVERSALIDAD A LOS EXTRANJEROS EN ESPAÑA. EL CASO DE LA PRESTACIÓN POR HIJO O MENOR A CARGO}

Nuestro ordenamiento jurídico, a través del artículo 39 de la Constitución española de 1978, y siguiendo lo establecido para nuestro sistema de seguridad social expuesto, en numerosas ocasiones establece la obligatoriedad de los poderes públicos de garantizar la protección a las familias como parte del sistema de protección social. ${ }^{50}$

Partimos de la base de que el extranjero ya está en situación administrativa regular en España y, una vez obtenida ésta, hemos determinado que gozan de los mismos derechos que un nacional en materia de seguridad social; llegados a este punto, nos encontramos con un problema común: el disfrute de las prestaciones por beneficiarios que no han optado por la reagrupación familiar y que siguen manteniendo su residencia en el país de origen de la persona que genera el derecho a la prestación.

Una vez obtenida la residencia, el extranjero en situación administrativa regular en España tiene los mismos derechos en materia de seguridad social que los nacionales, lo que incluye, lógicamente, las prestaciones reconocidas en el sistema y, por lo tanto, todas las prestaciones familiares, siempre y cuando cumplan los requisitos que se exijan para cada una de ellas; del mismo modo, sus familiares tendrán derecho de acceso a las prestaciones que se les reconozcan por su condición de beneficiarios.

En 1990, tras la aprobación de la Ley 26/1990, del 20 de diciembre, de prestaciones no contributivas, se comienza a considerar la cuantía de los ingresos de las familias para conceder la prestación por hijo o menor a cargo, por lo que podemos entender que la misma se convierte en un instrumento de lucha contra la pobreza de la sociedad, es decir, se concibe para suplir situaciones de necesidad de aquellas familias más desfavorecidas económicamente, y, en concreto, de los hijos o menores a su cargo; se encuentra dentro de las prestaciones pensadas para proteger a las familias con menores recursos económicos. ${ }^{51}$

Uno de los problemas que aparecen con mayor asiduidad es que dichas prestaciones dependan de la residencia del familiar en nuestro país, ya que en

50 Sánchez-Urán Azaña, Y., "Derecho a la protección social como factor de integración del inmigrante. La dialéctica universalidad/ciudadanía”, cit., pp. 249-296.

51 Obiol i Francés, S., "El sistema de prestaciones por hijo a cargo en España", Revista Internacional de Sociología, 2006, pp. 95-117. 
muchas ocasiones no se ha producido la reagrupación familiar, y, por tanto, los perceptores pierden el derecho por no cumplir con uno de los requisitos exigidos legalmente (lo mismo ocurrirá con las prestaciones de vejez e invalidez, donde uno de los requisitos de acceso específicos para extranjeros es establecer un periodo de residencia determinado en nuestro país); y, al tiempo, existen otras prestaciones, como es el caso de las prestaciones por muerte y supervivencia, que, a diferencia de las anteriores, no exigen requisito de residencia.

El derecho a la prestación por hijo a cargo se produce cuando éste es menor de dieciocho años, o, en su defecto, cuando siendo mayor de dicha edad tiene un grado de discapacidad igual o superior al 65\% y siempre y cuando se encuentre a cargo del beneficiario de la asignación; el artículo 352 del TRLGSS 52 establece claramente cuáles van a ser las exigencias para poder optar a la citada prestación, y entre ellas establece que la residencia, tanto del beneficiario como del hijo a cargo, deben estar fijadas en territorio español..$^{53}$

En la Ley 26/1990, del 20 de diciembre, de prestaciones no contributivas, se preveía la prestación no contributiva por hijo a cargo, si bien es cierto que no establecía que éstos residieran en territorio español, ${ }^{54}$ lo único que implantaba era que debía estar a cargo del solicitante, obviamente, y que cumplieran los requisitos de edad o discapacidad; ${ }^{55}$ pero es en el RD 356/1991, 56 del 15 de marzo ${ }^{57}$ cuando el legislador, al desarrollar la Ley 26/1990,58 del 20 de diciembre, introduce por primera vez como requisito para disfrutar de la prestación, la convivencia del hijo a cargo con el progenitor en territorio español, ${ }^{59}$ lo que

52 Real Decreto Legislativo 8/2015, del 30 de octubre, por el que se aprueba el texto refundido de la Ley General de la Seguridad Social.

53 Barrios Baudor, G. L., Prestaciones familiares por hijos a cargo, Aranzadi, 2001.

54 Álvarez del Cuvillo, A., "Residencia de los extranjeros extracomunitarios y prestaciones familiares de seguridad social", Temas Laborales. Revista Andaluza de Trabajo y Bienestar Social (96), 2008, pp. 97-134.

55 Pumar Beltrán, N., "Protección social y familiares de las personas trabajadoras extranjeras en España”, El futuro europeo de la protección social, cit., pp. 251-261.

56 Vigente hasta el 23 de noviembre de 2005.

57 Real Decreto 356/1991, del 15 de marzo, por el que se desarrolla, en materia de prestaciones por hijo a cargo, la Ley 26/1990, del 20 de diciembre, por la que se establecen en la seguridad social prestaciones no contributivas.

58 Ley 26/1990, del 20 de diciembre, por la que se establecen en la seguridad social prestaciones no contributivas.

59 Flor Fernández, M. L. "Prestaciones familiares por hijo a cargo en la ley 26/90 de 20 de diciembre", Los derechos de información en la empresa, las prestaciones no contributivas: X Jornadas 
sin duda alguna alejaba dicha prestación del derecho de igualdad, ya que no trata a todos los hijos del causante del mismo modo, únicamente basándose en el hecho de la convivencia en territorio español, ${ }^{60} \mathrm{y}$ así lo establecía en su artículo 2.1.

A colación de la aprobación del RD 356/1991, el Tribunal Supremo estuvo reconociendo el derecho a las prestaciones de este tipo a hijos que residían en el país de origen de los causantes de la prestación; así pues, el Tribunal Supremo reconocía la prestación a todos los miembros de la unidad familiar que sean económicamente dependientes del beneficiario aunque no tengan el mismo domicilio que éste; ${ }^{61}$ ello supondría el derecho a la percepción de la prestación por hijo a cargo; desde el punto de vista de lo establecido en estas STS, la interpretación para la concesión de la prestación por hijo a cargo vendría determinada según lo previsto en el artículo 1g) del Convenio 157 de la OIT, ${ }^{62}$ dependiendo únicamente la concesión de la prestación a la exigencia de que el beneficiario de la misma tenga realmente a los hijos a su cargo.

El principio de igualdad en materia de seguridad social entre extranjeros y españoles, ya se ha nombrado muchas veces a lo largo de este trabajo (recordar que viene regulado en el artículo 7 del TRLGSS); hay que destacar que establece una limitación real al principio de territorialidad; es decir, España, si dejara de lado los mandatos internacionales y europeos no tendría la obligación real de aplicar el principio de igualdad en el derecho a la seguridad social, y, por analogía, tampoco tendría la obligación de subsanar hechos que ocurran fuera del territorio español (como es el caso de la residencia de los hijos dependientes del beneficiario en su país de origen por no haber optado al derecho de agrupación familiar por una u otra razón).

España es responsable, en materia de seguridad social, en aquellos casos en los que el problema se plantee dentro de nuestras fronteras, ya que se aleja del control administrativo la capacidad de vigilancia de la veracidad de la situación

Universitarias Andaluzas de Derecho del Trabajo y Relaciones Laborales, Trotta, Consejo Andaluz de Relaciones Laborales, 1992, pp. 297-304.

60 Álvarez del Cuvillo, A., "Residencia de los extranjeros extracomunitarios y prestaciones familiares de seguridad social”, cit., pp. 97-134.

61 STS del 11 de abril, número de recurso 2770/1999; STS del 3 de mayo de 2000, número de recurso 331/1999, y STS del 21 de enero de 2003, número de recurso 152/2002.

62 C157 - Convenio sobre la conservación de los derechos en materia de seguridad social, 1982 (núm. 157). Convenio sobre el establecimiento de un sistema internacional para la conservación de los derechos en materia de seguridad social (entrada en vigor: 11 de septiembre de 1986). Adopción: Ginebra, 68a. reunión CIT (21 de junio de 1982). 
concreta, si bien es cierto que el TJUE (antes TJCE), en varias ocasiones ha entendido que son discriminatorios todos aquellos criterios que condicionan el acceso a la prestación, a que ciertos hechos ocurran en el territorio del país que adjudica las prestaciones, y, así, ha entendido dicho tribunal que la residencia "no puede ser un requisito que limite el acceso a la prestación, suprima su concesión o reduzca su cuantía", ${ }^{63}$ pero únicamente cuando se refiere a Europa.

Cierto es que uno de los requisitos que se exigen en la prestación por hijos a cargo es que éstos residan en territorio español, por lo que existe, a mi parecer, una clara vulneración del derecho de igualdad de los no residentes frente a los hijos que sí residan, junto con sus progenitores, en territorio español, ya que, indiscutiblemente, que éstos residan o no en España no es condición necesaria para que se conviertan en dependientes de sus padres; es decir, un niño que resida en territorio no español, seguramente necesitará, del mismo modo que su progenitor, lo atienda económicamente para cubrir sus necesidades básicas.

Es necesario hacer mención al trabajo jurisprudencial que realizó el Tribunal Supremo al respecto, ya que en diversas ocasiones llegó a reconocer el derecho a la prestación por hijo a cargo a trabajadores extranjeros, cuyos familiares residían habitualmente en su país de origen, y lo hacía basándose, precisamente, en la diferencia existente entre convivir con un progenitor y depender de él para subsistir, y así lo hizo constar, cuando "los familiares sean sostenidos económicamente por el beneficiario, aun cuando no vivan bajo el mismo techo que éste". ${ }^{64}$

Con posterioridad, se aprobó la Ley 52/2003, del 10 de diciembre, ${ }^{65}$ en la que la prestación por hijo a cargo pasa a ser únicamente, una prestación no

63 Asunto C-228/88, Giovanni Bronzino contra Kindergeldkasse (petición de decisión prejudicial planteada por el Bayerisches Landessozialgericht). Seguridad social (derecho a prestaciones familiares cuando el derecho interno del país de empleo exige que los requisitos necesarios se cumplan en su territorio); Asunto C-321/93, José Imbernon Martínez contra Bundesanstalt für Arbeit (Petición de decisión prejudicial planteada por el Sozialgericht Nürnberg). Seguridad social (Asignaciones familiares) Residencia en el territorio nacional; Asunto C-266/95 Pascual Merino García contra Bundesanstalt für Arbeit (Petición de decisión prejudicial planteada por el Bundessozialgericht). Seguridad social de los trabajadores migrantes reglamento (CEE) núm. 1408/71 (Ámbito de aplicación personal). Concepto de trabajador por cuenta ajena (Prestaciones familiares).

64 SSTS del 11 de abril de 2000 (número de recurso 2770/1999), del 3 de mayo de 2000 (número de recurso 2770/1999), y del 21 de enero de 2003, entre otras (número de recurso 152/2002).

65 Ley 52/2003, del 10 de diciembre, de disposiciones específicas en materia de seguridad social. 
contributiva y se establece legalmente la obligatoriedad de que los hijos residan en territorio español junto con su progenitor. ${ }^{66}$ Debemos pensar quiénes son las personas más desfavorecidas con este cambio: lo habitual entre nacionales es que los hijos de éstos residan en territorio español junto a sus padres, ${ }^{67}$ por lo que los sujetos más afectados, lógicamente, son los extranjeros residentes en España que no hayan optado por la reagrupación familiar, de modo que, de nuevo, los requisitos legales no están enfocados a la consecución de la igualdad entre sujetos, ${ }^{68} \mathrm{y}$, por tanto, distamos de nuevo de la universalidad del sistema; lo que la legislación pretende y consigue con este precepto legal es diferenciar a los hijos a cargo de españoles y extranjeros, siempre con algunas salvedades. Es cierto que no se establece un trato diferenciado entre nacionales y extranjeros, ya que a ambos se les exige la convivencia con el progenitor, pero, obviamente, los hijos de nacionales españoles no vivirán en un país diferente al de los padres, como norma general, salvo en los casos establecidos en el artículo 2o. del RD 356/1991, ${ }^{69}$ del 15 de marzo, por el que se desarrolla, en materia de prestaciones por hijo a cargo, la Ley 26/1990, del 20 de diciembre, por la que se establecen en la seguridad social prestaciones no contributivas.

Visto esto, se debe recordar que el artículo 7o. del TRLGSS, en la redacción dada por el Real Decreto Legislativo 8/2015, ${ }^{70}$ del 30 de octubre, establece como obligatoria la igualdad de trato en materia de seguridad social entre extranjeros ${ }^{71} \mathrm{y}$ nacionales, pero también es cierto que establece una limitación atendiendo al principio de territorialidad, porque nuestro sistema no contempla la obligación de asimilar como propios aquellos hechos que ocurran fuera de nuestro territorio. Así pues, existe igualdad relativa entre nacionales y extranjeros, porque a pesar de que la ley les exige los mismos requisitos de acceso a la prestación, a mi parecer, es una desigualdad encubierta, ya que como mencioné anteriormente, el porcentaje más elevado de sujetos que se van a ver afectados por la diferente residencia entre padres e hijos a cargo van a

66 Pumar Beltrán, N., "Protección social y familiares de las personas trabajadoras extranjeras en España”, El futuro europeo de la protección social, cit., pp. 251-261.

67 Si no es con ambos sí, por lo menos, con uno de ellos, dependiendo de la situación familiar en la que se encuentren.

68 Hay que recordar que en este punto estamos hablando de extranjeros que residen legalmente en España, y que, por tanto, sus derechos deben ser equiparables a los de los nacionales.

69 Vigente hasta el 23 de noviembre de 2005.

70 Real Decreto Legislativo 8/2015, del 30 de octubre, por el que se aprueba el texto refundido de la Ley General de la Seguridad Social.

71 Siempre y cuando cumplan con los requisitos exigidos. 
ser, sin lugar a dudas, los extranjeros residentes en España que todavía tienen a sus hijos en sus países de origen.

Mientras sigan existiendo en nuestro sistema requisitos de residencia para optar a determinadas prestaciones, es imposible que la igualdad entre sujetos y, por tanto, la universalidad en el sistema, sean reales; es decir, seguimos observando cómo la universalidad en nuestro sistema es únicamente relativa. Es cierto que no aparece, directamente y como tal, una diferencia de trato; no obstante, si los observamos desde el punto de vista de la realidad social, seremos conscientes de que sí existe dicha diferencia de trato. En tal sentido, el TJUE ha entendido como discriminatorios los criterios que condicionan la percepción de una prestación estén ligados a que determinados hechos acaecidos en el territorio del país del que nace el sistema de prestaciones correspondiente, y, por tanto, ha calificado la "residencia" como un criterio que no puede limitar, suprimir o reducir la prestación; ${ }^{72}$ a tal efecto, muchos son los pronunciamientos del TJUE al respecto declarando discriminatorio el condicionamiento a la concesión de prestaciones familiares del trabajador a que sus familiares residan en el país que las concede, ${ }^{73}$ cierto es que, con base en esta jurisprudencia del TJUE, el requisito de residencia no puede ser exigido a ningún ciudadano de la Unión Europea ${ }^{74}$ ni a los nacionales extracomunitarios si son familiares de ciudadano español, ni a aquellos que tengan un convenio de cooperación con la Unión Europea, ${ }^{75}$ pero sí al resto de extranjeros. ${ }^{76}$

72 Pumar Beltrán, N., "Protección social y familiares de las personas trabajadoras extranjeras en España”, El futuro europeo de la protección social, Murcia, Laborum, 2010, pp. 251261.

73 Asunto C-228/88 Giovanni Bronzino contra Kindergeldkasse (petición de decisión prejudicial planteada por el Bayerisches Landessozialgericht). Seguridad social (derecho a prestaciones familiares cuando el derecho interno del país de empleo exige que los requisitos necesarios se cumplan en su territorio); Asunto C-321/93, José Imbernon Martínez contra Bundesanstalt für Arbeit (Petición de decisión prejudicial planteada por el Sozialgericht Nürnberg). Seguridad social (Asignaciones familiares) Residencia en el territorio nacional; Asunto C-266/95 Pascual Merino García contra Bundesanstalt für Arbeit (Petición de decisión prejudicial planteada por el Bundessozialgericht). Seguridad social de los trabajadores migrantes, reglamento (CEE) núm. 1408/71 (Ámbito de aplicación personal). Concepto de trabajador por cuenta ajena (prestaciones familiares).

74 Pumar Beltrán, N., "Protección social y familiares de las personas trabajadoras extranjeras en España”, El futuro europeo de la protección social, cit., pp. 251-261.

75 Turquía, Argelia, Túnez y Marruecos (febrero de 2017).

76 Aunque es cierto que el TJUE ha permitido en Reino Unido que se exija la residencia de los hijos para el cobro de prestaciones por hijo a cargo, incluso para miembros de la Unión Europea, cuando no llevan a cabo trabajo remunerado alguno. En Urcelay Lecue, M. C. (2016). 
Es justificable que tanto el nacimiento como el mantenimiento del derecho a la prestación por hijo a cargo esté supeditado al requisito de la residencia legal en España tanto del beneficiario de la misma como de los hijos de éste, si bien hay que resaltar que existen algunas excepciones legales a tal exigencia; así pues, estarán exentos de cumplir con estos requisitos a tenor de lo establecido en los artículos 9.1.2 y 10.1.a) del Real Decreto 1335/2005, ${ }^{77}$ de 11 de noviembre, por el que se regulan las prestaciones familiares de la seguridad social, siempre y cuando los hijos cesen la convivencia con los padres por cursar estudios, trabajo de los padres, tratamientos médicos, rehabilitación, o cuando los padres trabajen fuera del territorio español, pero coticen a nuestro sistema de seguridad social; ahora bien, que sea justificable como mecanismo de control del Estado no significa que no pugne contra el principio de igualdad que, a mi entender, se vulnera en los requisitos de acceso a esta prestación, y que, por tanto, afecta de manera directa a la universalidad real de la misma y, con ello, del sistema.

\section{CONCLUSIONES}

Se debe aceptar la migración como un fenómeno social y global desde finales del siglo XX en nuestro país, y, por tanto, hay que tomar especial atención con lo que ocurre con estas personas sin olvidar, precisamente, que son personas, y que, por tanto, son sujetos titulares de los derechos humanos.

Con la aplicación de las normas internacionales, europeas y comunitarias, en consonancia con el ordenamiento jurídico interno, es cierto que estamos ante una situación que, aunque cambiante en el tiempo, ha llevado a situaciones que no estaban protegidas, para después protegerlas de manera muy amplia, y, en estos momentos, alcanzar una postura intermedia, si bien es cierto que se ha llegado, por ejemplo, a la equiparación total de acceso al sistema de seguridad social a todos aquellos trabajadores extranjeros que se encuentren en España en situación administrativa regular, y, sin lugar a dudas, las normas internacionales han sido, en gran medida, las que han propiciado la extensión del sistema de seguridad social a este colectivo en particular.

El TJUE permite al Reino Unido exigir "derecho de residencia" a los ciudadanos UE, que no ejercen actividad económica, para percibir prestaciones por hijo a cargo. Revista Aranzadi Doctrinal, (8), pp. 191 y 192.

77 Real Decreto 1335/2005, del 11 de noviembre, por el que se regulan las prestaciones familiares de la seguridad social. 
En cuanto a la consideración de los extranjeros en la Constitución española de 1978, se puede pensar que el constituyente, a tenor de lo establecido en los artículos 10.2 y 13.1 de la misma, optó por la universalidad real del sistema, incluyendo a todas las personas en el ámbito del disfrute de los derechos sociales, pero también es cierto que ambos preceptos son los que conceden total libertad al legislador para regular las normas relativas a extranjería, respetando siempre la dignidad de las personas y lo establecido en los mandatos internacionales y comunitarios, pero el legislador lo ha interpretado de tal modo que ha generado avances y retrocesos en dicho sistema normativo.

La consideración de extranjero (sin tener en cuenta al comunitario) supone una diferenciación en el régimen jurídico aplicable al mismo y que ha variado mucho desde 1985, cuando se aprobó la Ley Orgánica 1/1985, sobre derechos de los extranjeros en España; pero es cierto que el legislador ha debido ir adaptando todas las normas de extranjería en función de las necesidades de cada época para, definitivamente, agregar a dichas normas el carácter que hace que se diferencien en menor medida de los nacionales; así, la actual ley que regula el derecho de los extranjeros en España incluye, además, su integración social en España, concepto que se introdujo con la LO 4/2000.

La LO 4/2000 ha sufrido diversas modificaciones, la última de ellas operada por la Ley Orgánica 2/2009, del 11 de diciembre. En ella se regula la situación de los extranjeros en España y los diferencia a la hora de la aplicación de los derechos, de nuevo, en función de su situación administrativa (regular o irregular).

Nuestro ordenamiento jurídico exige a los extranjeros la obtención de autorizaciones de residencia y trabajo para poder prestar sus servicios como trabajadores en España para que los efectos, además, de nuestras normas laborales, y, por tanto, de las normas de seguridad social, sean de aplicación a los mismos, en idénticas circunstancias a los nacionales.

No suelen presentarse problemas en cuanto al principio de igualdad y universalidad en este sentido, si bien es cierto que aparecen ciertas fisuras en el sistema, en que la regulación de las prestaciones afecta de manera distinta a extranjeros regulares y nacionales. Un claro ejemplo de ello es la prestación por hijo o menor a cargo, que si bien no establece una regulación diferente, sí supone una diferencia entre ambos, ya que la residencia del hijo o menor a cargo va a determinar la concesión o no de dicha prestación. Si bien es cierto que las exigencias legales para unos y otros son idénticas, la residencia en España de esos hijos afecta en mayor medida a extranjeros que a nacionales. 


\section{BIBLIOGRAFÍA}

Álvarez Cortés, J. C. y Plaza Angulo, J. J., "Prestaciones de seguridad social. Sobre la imposibilidad de acceder a la protección por desempleo por los trabajadores inmigrantes en situación irregular", Temas Laborales: Revista Andalura de Trabajo y Bienestar Social, 2008.

Álvarez Del Cuvillo, A., "Residencia de los extranjeros extracomunitarios y prestaciones familiares de seguridad social", Temas Laborales. Revista Andaluza de Trabajo y Bienestar Social (96), 2008.

Barrios Baudor, G. L., Prestaciones familiares por hijos a cargo, Aranzadi, 2001.

Charro BAENA, P., “Trabajadores extranjeros «ilegales» y accidente de trabajo y enfermedad profesional. Cobertura en el sistema de seguridad social", Accidentes de trabajo y enfermedades profesionales, Cizur Menor (Navarra), Aranzadi, 2007.

FERNÁNDEZ BERNAT, J. A., "Asistencia sanitaria e inmigración irregular", Revista de treball, economia i societat, núm. 67, 2013.

FLOR FERnÁNDEZ, M. L., "Prestaciones familiares por hijo a cargo en la ley 26/90 de 20 de diciembre", Los derechos de información en la empresa, las prestaciones no contributivas: $X$ jornadas universitarias andaluzas de derecho del trabajo y relaciones laborales, Trotta, Consejo Andaluz de Relaciones Laborales, 1992.

LÓPEZ LÓPEZ, J., "Una mirada a los derechos sociales de los inmigrantes desde su dignidad", Estudios de Derecho Judicial, 2005.

MARTínez Fons, D., "Los efectos del despido de los trabajadores extranjeros que carecen de autorización administrativa para trabajar en España. Sentencia del Tribunal Superior de Justicia de Castilla y León de 17 de noviembre de 2005 (AS 3384)", Iuslabor, 2006.

Montoya Melgar, A., El empleo ilegal de inmigrantes, Cizur Menor, Navarra, Thomson-Civitas, 2007.

Montoya Melgar, A., "El empleo ilegal de inmigrantes", Revista de Derecho de la Unión Europea, 2009.

Moreno Pueyo, M. J., "Extranjeros inmigrantes y seguridad social española, Estudios Financieros". Revista de Trabajo y Seguridad Social. Comentarios, Casos Prácticos. Recursos Humanos, 2004. 
OBIOL I FRANCÉS, S., "El sistema de prestaciones por hijo a cargo en España”, Revista Internacional de Sociología, 2006.

ORTEGA GimÉNEZ, A., "El derecho a la prestación por desempleo de los extranjeros irregulares, tras la sentencia del tribunal supremo de 18 de marzo de 2008", Actualidad Jurídica Aranz̧adi, 2008.

Pumar Beltrán, N., "Protección social y familiares de las personas trabajadoras extranjeras en España", El futuro europeo de la protección social, Murcia, Laborum, 2010.

RAmos QuiNTANA, M. I., "El trabajo de los inmigrantes extracomunitarios. Situaciones administrativas y posición jurídica: Ponencia temática II", Derechos y libertades de los extranjeros en España: XII Congreso Nacional de Derecho del Trabajo y de la Seguridad Social, Santander, Gobierno de Cantabria, Consejería de Industria, Trabajo y Desarrollo Tecnológico, 2003.

RAMOS QUINTANA, M. I., “Inmigración y globalización económica: ¿un lugar para el derecho del trabajo?”, Revista del Ministerio de Trabajo e Inmigración, 2006.

Rivera SÁNCHEZ, J. R., "La acción protectora derivada de contingencias profesionales a los trabajadores extranjeros en situación irregular: Comunicación a la ponencia temática III", Derechos y libertades de los extranjeros en España: XII Congreso Nacional de Derecho del Trabajo y de la Seguridad Social, Santander, Gobierno de Cantabria, Consejería de Industria, Trabajo y Desarrollo Tecnológico, 2003.

Rodríguez-PiÑero Royo, M., "Principio de igualdad y estatuto del trabajador inmigrante", Relaciones Laborales. Revista Crítica de Teoría y Práctica, 2001.

SÁNCHEZ PÉREZ, J., "El accidente de trabajo del inmigrante «sin papeles»". Actas del I Congreso Internacional sobre Migraciones en Andalucía, Universidad de Granada, Instituto de Migraciones, 2011.

SÁnchez Rodas-Navarro, C., Derechos sociales, garantías y restricciones de los inmigrantes en situación irregular en la unión europea, Murcia, Laborum, 2008.

SÁnchez-Rodas NaVArRo, C. y Vicente Palacio, M. A., "Las prestaciones familiares. Presentación", Revista General de Derecho del Trabajo y de la Seguridad Social (32), 2012.

SÁNCHEZ-URÁN AZAÑA, Y., "Derecho a la protección social como factor de integración del inmigrante. La dialéctica universalidad/ciudadanía", Revista del Ministerio de Trabajo e Inmigración, 2006. 
SiRVENT HERNÁNDEZ, N., "La residencia legal como requisito de acceso a la protección de seguridad social de los extranjeros extracomunitarios", Revista General de Derecho del Trabajo y de la Seguridad Social, 2009.

Triguero MARTíneZ, L. A., El estatuto jurídico laboral del trabajador extranjero inmigrante, Albacete, Bomarzo, 2008. 